\title{
LONG-TERM REPRODUCTIVE OUTPUT IN WESTERN GULLS: CONSEQUENCES OF ALTERNATE TACTICS IN DIET CHOICE
}

\author{
Cynthia A. Annett and Raymond Pierotti \\ Division of Biological Sciences, University of Kansas, Lawrence, Kansas 66045-2106 USA
}

\begin{abstract}
Numerous studies reveal strong, positive skews in long-term breeding performance among free-living animals, yet few studies explore the mechanisms underlying such variation. We examine the results of a 12-yr study of a population of Western Gulls, Larus occidentalis. Of 112 pairs for which we have either long-term ( $\geq 5 \mathrm{yr}$ ) or lifetime reproductive output, $44 \%$ bred for only a single year, and an additional $25 \%$ bred for only 2-3 yr. A few pairs bred successfully for 6-12 yr and showed higher average clutch size, hatching success, and fledging success within any single season than did less successful breeders. The principal trait influencing both survival and reproduction was individual diet, which consisted of a mix of human refuse and fish. A strong, positive relationship existed among the amount of fish taken, breeding life-span, and reproductive performance. Birds with short life-spans took little or no fish on an annual basis. Birds with breeding lifespans $>10 \mathrm{yr}$ and high breeding success took $>60 \%$ fish. Diet choice was also important for successful recruitment; $90 \%$ of banded offspring returning to breed on the colony had parents that had taken predominantly fish. Diets of male, but not female, recruits were correlated with diets of their parents; $90 \%$ of male recruits banded as chicks in the colony were successful breeders, in contrast to $10 \%$ of other recruits. Despite apparent selective advantages, few recruits take a diet consisting predominantly of fish, which suggests the existence of at least two alternate tactics, i.e., highly risk-prone foraging for fish, or riskaverse foraging for refuse. This suggests that diet choice is passed between generations by means such as learning or cultural transmission from parents to offspring.

Key words: alternate tactics; foraging; seabird; Larus occidentalis; life history; Western Gull.
\end{abstract}

\section{INTRODUCTION}

Studies of reproductive performance have long been key elements of evolutionary ecology, because successful reproduction is directly related to fitness. Lifetime reproductive success (LRS: Clutton-Brock 1988, Newton 1989), defined as "the sum of the reproductive contributions from each of the ages to which an individual succeeds in surviving" (Partridge 1989), is a major component of fitness. In recent years, numerous studies investigating long-term or lifetime breeding performance have all revealed strong skews in both total reproductive life-span and reproductive performance, with the majority of individuals within populations showing little or no success, and a few individuals being highly successful and contributing most of the recruits to the next generation (papers cited in Clutton-Brock 1988, Newton 1989).

Only a few studies have examined the ecological factors that underlie this variation. In a population of red deer, Cervus elaphus, the most successful individuals occupied feeding areas where plants are high in protein (Clutton-Brock et al. 1982). Successful Great Tits, Parus major, breed for the first time in a strong mast year following a mild winter (Boyce and Perrins 1988). Only in Darwin's finches (Grant and Grant

Manuscript received 21 April 1997; revised 22 January 1998; accepted 9 February 1998.
1989), however, has the breeding success of offspring of the most successful individuals been studied in relation to factors that could influence long-term breeding success between generations.

Individual differences in foraging conditions or tactics appear to be a common factor affecting reproductive performance on both an annual and a long-term basis (cf. Pierotti and Annett 1987, 1990, 1991). LRS can be affected either by differences in foraging conditions early in life (Great Tit; Boyce and Perrins 1988), or by nutritional quality of forage (red deer; CluttonBrock et al. 1982). Similarly, beak size and associated differences in diet choice have been shown to have major effects on survival and reproduction among both pure and hybrid finches in the Galapagos (Grant and Grant 1989, 1994, 1996).

These differences in fitness suggest the existence of strong selective pressures that favor particular foraging strategies, in turn raising the question of how variance in foraging tactics is maintained in populations. Such "alternate tactics", within species may result when some individuals gain experience that makes them efficient foragers, or have access to high-quality feeding areas that are unavailable to other members of the population (Fretwell and Lucas 1970, Pierotti 1982, 1987, Ens et al. 1995, Grant and Grant 1996). Thus, alternate tactics may be the result of varying ecological condi- 
tions and, hence, may be phenotypic, but not necessarily genotypic, traits.

For Western Gulls, Larus occidentalis, on Southeast Farallon Island, annual variation in abundance of fish and differences in foraging efficiency between age classes are thought to influence several life history traits, including age of first reproduction, clutch size, hatching asynchrony, and fledging success (Pyle et al. 1991, 1997, Sydeman et al. 1991, Sydeman and Emslie 1992, Spear and Nur 1994). These investigators did not, however, quantify dietary variation among individuals, or the effects of individual variation in foraging efficiency on reproductive performance.

In this paper, we examine the relationship between individual variation in long-term reproductive performance and diet choice in Western Gulls. We have studied the breeding biology and ecology of a subcolony on Alcatraz Island in San Francisco Bay, California, since 1983. We have previously demonstrated that individual gulls on Alcatraz show two basic diets, feeding either on refuse or on fish. There is a significant relationship between the short-term reproductive performance of individual pairs and the composition of their diet (Pierotti and Annett 1987, 1990, Annett and Pierotti 1989). In this study, we extend these results to investigate whether variation in diet is correlated with long-term and lifetime, as well as annual, reproductive success.

\section{Study Organism and Methods}

Starting in 1983, we monitored reproductive output for each Western Gull pair on our subcolony by marking each egg with an indelible marking pen within $2 \mathrm{~d}$ of laying, and banding each chick upon hatching with individually numbered U.S. Fish and Wildlife Service leg bands. We also captured breeding adults and banded them for individual identification. Western Gulls typically do not change the location of their territories (Spear et al. 1987, Pyle et al. 1991, 1997), thus enabling us to monitor reproductive success each year for the same pairs and to determine reproductive life-spans of adult birds on our study colony.

Over a 12-yr period from 1983 to 1994 , we were able to obtain long-term data on performance until disappearance for 101 pairs, and continuing long-term ( $\geq 5$-yr) performance for an additional 11 pairs that remained active in breeding at termination of the study in 1994. Pairs were included in this data set if they were either (1) observed to initiate breeding after the initial year of our study in 1983 , or (2) were pairs breeding in 1983 that bred in multiple years following 1983. Pairs were not included in our analysis if they were only observed in 1983 and disappeared before the 1984 season. Therefore, our estimates of life-span or lifetime performance for pairs that may have initiated breeding prior to 1983 may be conservative. In addition, pairs in which mate switches occurred $(n=3)$ were not included in our analysis.
Western Gulls typically produce a clutch of three eggs, which constrains reproductive output to a maximum of three fledged chicks per year (Pierotti and Annett 1995). We monitored chick survival and condition either by direct measurement (for chicks with body mass $<500 \mathrm{~g}$ ), or through a spotting scope during nest watches (for chicks $>500 \mathrm{~g}$ ), which allowed us to assess the number of offspring fledged per nest.

Male Western Gulls typically do not initiate breeding until their fourth summer of life, and females usually do not start until their fifth summer (Ainley and Boekelheide 1991, Pierotti and Annett 1995, Pyle et al. 1997). Beginning in the fourth year of our study (1986), we checked band numbers of all banded breeding adults observed on the colony to identify offspring hatched on the colony that had recruited as breeding adults.

Nests were checked twice weekly from 1 May until 30 June, which covered the interval from pre-laying to hatching. During each nest check, all pellets, food remains, and other regurgitated material were removed from the territory so that they would not be recounted on subsequent visits. Separate records were maintained for food items found on each breeding territory throughout the breeding season. Because only the resident pair and their offspring were present on these territories, any food items found on a territory were assumed to be remains of food eaten by the resident pair. These data were then used to describe the diet of that particular pair.

Data on the composition and temporal patterning of diet for each pair were collected using three principal methods (Pierotti 1981, 1987, Pierotti and Annett 1987, 1990, 1991). First, gulls regurgitate pellets, consisting of undigested portions of food, around their nesting territories. We collected, counted, and analyzed contents of these pellets. Second, adults and chicks captured for the purpose of banding or weighing regurgitate the contents of their proventriculus. These regurgitants may be easily identified as to contents, including species, age class, and sex of fishes and marine invertebrates.

The third method for identifying food items consisted of observing bouts of mate and chick feeding from a blind during nest watches conducted for 2-3 h during each visit to the colony. Using telescopes and binoculars to observe transfer of food, we were able to identify type, size, and, on occasion, even number of food items. After termination of nest checks on 30 June, we continued to collect data on chick and mate feedings during 3-4 h observation periods conducted twice weekly.

Combined data from pellets, regurgitations, and chick and mate feeding observations were used to generate annual diets for each pair monitored. The annual diet was recorded as the percentage of days during which fish were included in the diet of each pair for which we had at least 10 separate daily records of food items (see also Pierotti and Annett 1987, 1990, 1991). 


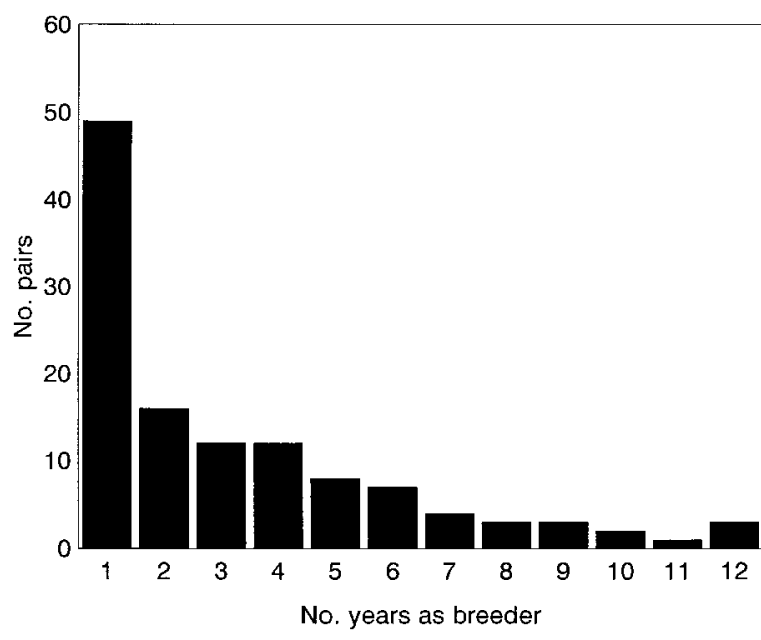

FIG. 1. Distribution of breeding life-spans for pairs of individually recognizable Western Gulls during a 12-yr study on Alcatraz Island, California, USA. Number of years as breeder is defined as the number of years in which that individual occupied a breeding territory and produced a clutch of at least one egg.

A lifetime diet for each pair was calculated by averaging among annual diets. For those pairs that bred for only a single year, their diet during that year is given as their lifetime diet.

We assessed the strength of potential selection pressure using the opportunity for selection $(I) . I$ is estimated using the ratio of the variance in reproductive success to the square of mean reproductive success: $I=$ variance/mean ${ }^{2}$ (Arnold and Wade 1984, Endler 1986, Downhower et al. 1987). This value serves as an index of the variation that is potentially subject to selection in a given population, so that if the variance is larger than the mean value squared, then opportunity for selection exists.

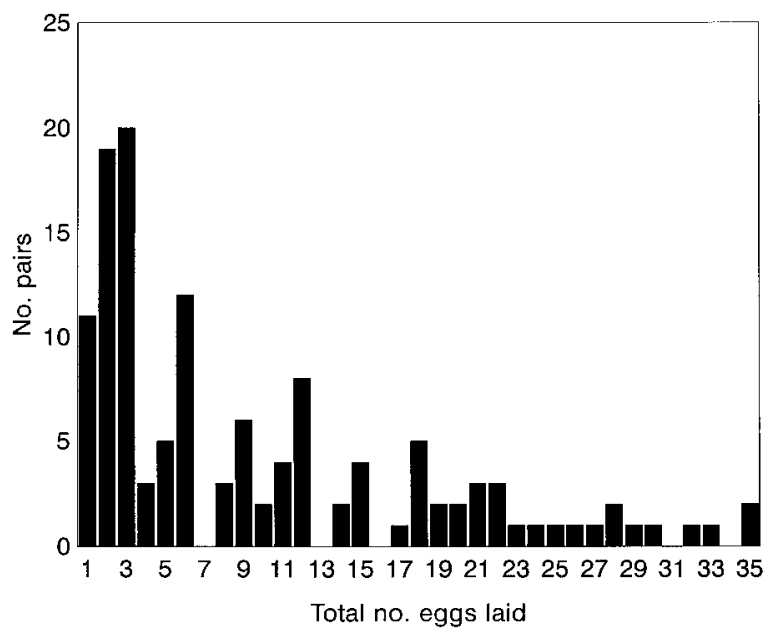

FIG. 2. Distribution of the total number of eggs laid over the breeding life-span for pairs of individually recognizable Western Gulls during study on Alcatraz Island, California.

\section{Results \\ Average breeding performance and population phenomena}

Our data reveal that, over the 12 years of our study, the average breeding life-span of Western Gulls was $4.0 \pm 3.11$ seasons (all data reported as mean $\pm 1 \mathrm{SD}$ ), which is similar to mean breeding life-spans of many large, white-headed Larus gulls (Paynter 1966, Kadlec and Drury 1968). During this reproductive life-span, the average pair on Alcatraz produced $10.8 \pm 9.24$ eggs, yielding a mean annual clutch size of 2.7 eggs. From these eggs, an average Alcatraz pair successfully hatched $8.7 \pm 8.58$ chicks over their life-span, yielding an annual hatching success of 2.2 chicks/yr. Of these chicks, $7.1 \pm 7.54$ fledged per pair, on average, yielding an annual fledging success of $\sim 1.8$ fledglings/yr.

These results describe a population potentially increasing at a substantial rate. If we assume $40 \%$ survival from fledging to first reproduction (Spear and Nur 1994, Pyle et al. 1997), an average pair fledging 7.1 chicks will produce 2.8 breeding adults over its breeding lifetime, yielding a net reproductive rate $R_{0}=1.42$. This value of $R_{0}$ indicates that the Alcatraz population should double after approximately two generations. This estimated rate of growth is supported by our observation that, over the first 10 years of our study (two generations, because the generation time of female gulls is $5 \mathrm{yr}$ ), the breeding population of Western Gulls on Alcatraz doubled in size, increasing from $\sim 250$ pairs in 1983 to $>500$ pairs in 1992 .

It should also be noted, however, that for all reproductive parameters, i.e., total number of eggs laid, chicks hatched, and chicks fledged, the standard deviations are comparable in magnitude to the mean. The magnitude of these standard deviations indicates that there is high opportunity for a strong selective response. The opportunity for selection in our study population, $I=1.13$ (based on the lifetime number of fledged chicks), is higher than all but one previous estimates of $I$ for females and monogamous males in free-living populations (Downhower et al. 1987).

\section{Individual long-term reproductive output}

Our results indicate that there is a strong, positive skew in the distribution of breeding performances. Most Western Gull pairs have a short reproductive lifespan and little success, whereas a few birds have long life-spans and high success (Figs. 1-4). For example, although mean breeding life-span was $4.0 \mathrm{yr}, 44 \%$ (49 pairs) bred only a single season before disappearing, and $69 \%$ of pairs (77 pairs) did not make it to a fourth breeding season (Fig. 1). In contrast to these less successful pairs, $28 \%$ (31 pairs) bred for $\geq 5 \mathrm{yr}$ during the study, and $5 \%$ (6 pairs) bred for $\geq 10 \mathrm{yr}$ (Fig. 1).

Modal lifetime production was three eggs, and $45 \%$ (50 pairs) produced three or fewer eggs over their breeding lifetime (Fig. 2). However a substantial frac- 


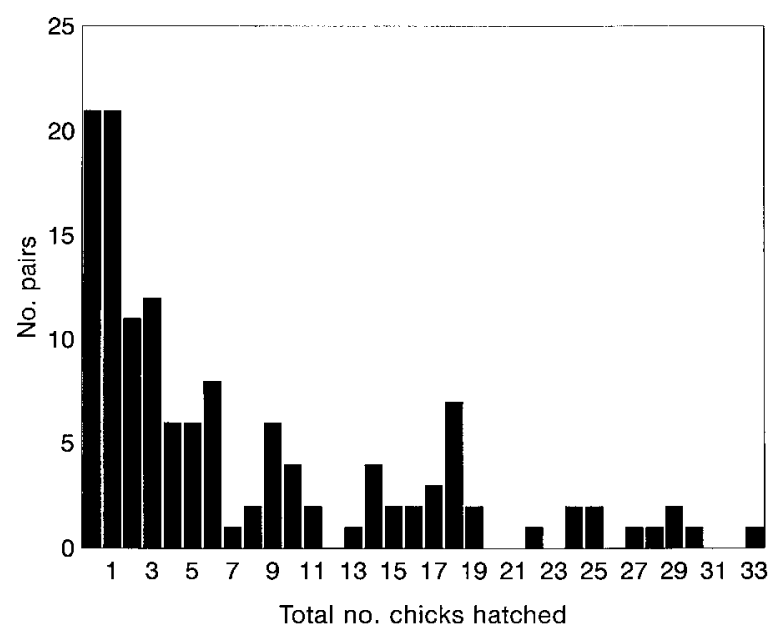

FIG. 3. Distribution of the total number of chicks hatched over the breeding life-span for pairs of individually recognizable Western Gulls during study on Alcatraz Island, California.

tion of pairs was quite successful: $26 \%$ (29 pairs) laid $>15$ eggs and $4 \%$ (5 pairs) laid $\geq 30$ eggs (Fig. 2).

With regard to chick production (hatching of eggs), 22 pairs $(20 \%)$ hatched zero chicks and 22 pairs $(20 \%)$ hatched one chick, the most common numbers of chicks hatched per breeding lifetime (Fig. 3). If we assume survival from hatching to fledging of $\sim 80 \%$ (Table 1 ) and a survival rate from fledging to first reproduction of $\sim 40 \%$ (Spear and Nur 1994, Pyle et al. 1997), a pair should hatch a minimum of six chicks to replace themselves over their breeding life-span. Overall, 69\% (77 pairs) failed to hatch six chicks over their breeding lifespans. In contrast, 9\% (11 pairs) hatched $>20$ chicks (Fig. 3).

Over a lifetime, the modal number of chicks fledged per pair was zero (35 pairs; $31 \%$ ). To replace themselves in the population, a pair must fledge at least five offspring. Only 37 pairs (33\%) achieved this total (Fig. 4 ). Nine pairs ( $8 \%$ ) fledged $\geq 20$ chicks, however; these pairs represent $>25 \%$ of the chicks produced on the subcolony during the entire 12 years of the study.

A positive correlation existed between lifespan and fecundity, because individuals that produced the most eggs and chicks had the longest life-spans. These individuals had high reproductive success on an annual, as well as long-term, basis. Because clutch size in gulls is constrained to three eggs, there is little potential variation in clutch size. Despite this constraint, pairs with breeding life-spans that exceeded the mean breeding life-span $(4.0 \mathrm{yr})$ produced clutch sizes $0.5 \mathrm{egg}$ greater, on an annual basis, than did pairs that bred for the mean number of years or less (Table $1 ; P<0.001$ using a $t$ test, with $82 \mathrm{df}$ ). Pairs with breeding lifespans that exceeded the mean also hatched one more egg per year, on average, than did pairs breeding for the mean number of breeding years or less, and had a
TABLE 1. Comparison of annual breeding performance of birds that bred for $\geq 5 \mathrm{yr}$ and birds that bred for $<5 \mathrm{yr}$. Data are presented as mean \pm 1 SD.

\begin{tabular}{lcccc}
\hline \hline $\begin{array}{l}\text { Breeding } \\
\text { life-span }\end{array}$ & $n \dagger$ & $\begin{array}{c}\text { Clutch } \\
\text { size }\end{array}$ & $\begin{array}{c}\text { Hatching } \\
\text { success }\end{array}$ & $\begin{array}{c}\text { Fledging } \\
\text { success }\end{array}$ \\
\hline$\geq 5 \mathrm{yr}$ & 29 & $2.78 \pm 0.290$ & $2.39 \pm 0.394$ & $2.02 \pm 0.430$ \\
$<5 \mathrm{yr}$ & 55 & $2.39 \pm 0.731$ & $1.40 \pm 1.076$ & $0.99 \pm 0.910$
\end{tabular}

Note: For all three measures of breeding performance, $t$ test differences between pairs breeding $\geq 5 \mathrm{yr}$ and pairs breeding $<5$ yr were significant at $P<0.001$.

$\dagger$ Sample size is number of pairs.

markedly higher rate of successfully hatching eggs (the egg/hatch ratio was $86 \%$ for pairs breeding $\geq 5 \mathrm{yr}$, and $59 \%$ for pairs breeding $<5 \mathrm{yr} ; P<0.01$ by $\chi^{2}$ test). With regard to fledging performance, pairs with breeding life-spans that exceeded the mean fledged one more chick per year than did pairs with a mean or shorter breeding life-span, and had much higher rates of fledging success. The egg/fledge ratio was $73 \%$ for pairs breeding $\geq 5 \mathrm{yr}$ and $41 \%$ for pairs breeding $<5 \mathrm{yr}$; $(P$ $<0.001$ by $\chi^{2}$ test); the hatch/fledge ratio was $85 \%$ for pairs breeding $\geq 5 \mathrm{yr}$, and $71 \%$ for pairs breeding $<5$ yr $\left(P<0.05\right.$ by $\chi^{2}$ test $)$. These results suggest that, although life-span serves as an important predictor of long-term reproductive performance, there are important differences in quality between individuals with short and long reproductive life-spans.

Breeding experience may influence reproductive success, with first-year breeders fledging significantly fewer chicks than more experienced birds (Sydeman et al. 1991, Sydeman and Emslie 1992). Thus, pairs with short breeding life-spans may also show lower average reproductive success. Excluding all pairs breeding in 1983, the average pair on our study colony fledged 0.99

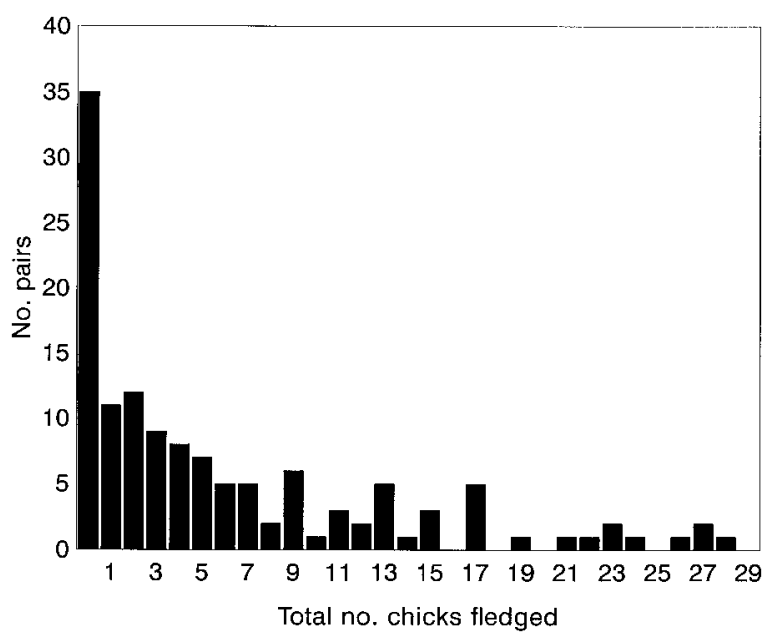

FIG. 4. Distribution of the total number of chicks fledged over the breeding life-span for pairs of individually recognizable Western Gulls during study on Alcatraz Island, California. Fledged offspring are chicks that survive to become independent of their parents. 


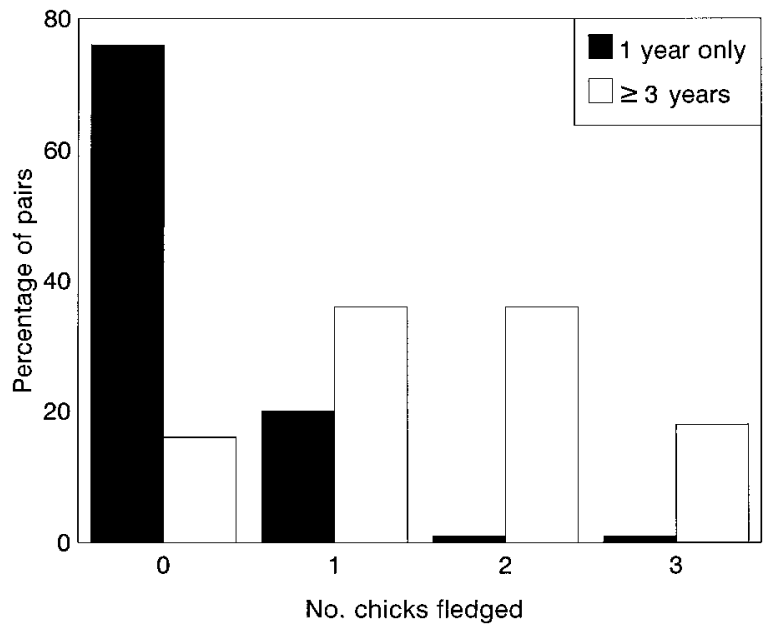

FIG. 5. Distribution of fledging success during the initial year of reproduction for pairs that bred for only a single year vs. pairs that bred for at least three years.

\pm 1.02 chicks $(n=82)$ during their initial breeding season. This overall success is only slightly more than half of the overall fledging success of 1.8 fledglings/ yr for all pairs, suggesting that first-time breeders do have lower success than more experienced birds.

If these data are examined more closely, however, a different pattern emerges. Fledging success for pairs that bred only a single season before disappearing ( $n$ $=41$ ) was only $0.32 \pm 0.65$ fledglings/yr, and only one pair that bred for a single season fledged three chicks (Fig. 5). In contrast, pairs that bred for at least three seasons did not show low breeding performance during their first year. Fledging success in their first year was $1.44 \pm 0.89$ chicks, which is not significantly different than fledging success in their third year (1.67 $\pm 0.83, n=41$ pairs). Many pairs did not improve between their first and third seasons; 11 pairs had poorer success, 18 had equal success, and 16 pairs had better success, a result that is not statistically significant. These results suggest that the lower lifetime performance of birds with short reproductive life-spans is not a result of overall poorer performance of all pairs during their first year, but a difference in quality between short- and long-term breeders that is manifested even during the initial breeding season.

\section{Diet choice and LRS}

The principal trait that appeared to influence both survival and reproduction was the diet taken by individuals. Western Gulls on Alcatraz took two major types of food over the 12 years of this study: (1) human refuse, which was mostly chicken and pork scraps, but contained numerous other components; and (2) fish, which are natural prey (Annett and Pierotti 1989). The most common fish in gull diets were anchovies (Engraulis spp.), plainfin midshipman (Poricthys notatus), jacksmelt (Trachurus symmetricus), and white croaker
(Genyonemus lineatus), all of which were abundant in San Francisco Bay and its surrounding waters.

The diets of individual pairs showed considerable variation in proportion of these two primary food sources, with pair diets ranging from those consisting almost entirely of fish to those consisting entirely of human refuse (Fig. 6). The single most common diet was represented by 23 pairs $(21 \%)$ that were never observed to take fish during their breeding life-spans. Most of these pairs bred for only one season and failed to fledge any offspring; only one of these pairs bred for as many as three seasons, and only two fledged as many as two chicks over their breeding life-spans.

Aside from these refuse specialists, the distribution of diets was roughly symmetrical, but skewed slightly toward diets low $(<50 \%)$ in fish (Fig. 6). The mean fraction of fish in the diet was $\sim 40 \%(0.39 \pm 0.277)$. Most pairs took diets ranging from $30 \%$ to $60 \%$ fish, and took primarily refuse during the incubation period, but switched to a fish diet around the time when their chicks hatched (Annett and Pierotti 1989). A few pairs, however, took diets that were predominantly $(60 \%$ to $>90 \%$ ) fish.

Overall, there is a strong, positive relationship between the amount of fish taken by individual pairs and their breeding life-span (Fig. $7 ; r^{2}=0.58$ for diet vs. life-span; $P<0.001$ ). Only two of 31 pairs with breeding life-spans $>5 \mathrm{yr}$ had diets consisting of $<50 \%$ fish on an annual basis. Only one pair that took $\geq 60 \%$ fish had a breeding life-span $<4$ yr. Only one pair that took $>80 \%$ fish had a breeding life-span $<5 \mathrm{yr}$; this pair bred successfully for three years in a row, and only failed in their fourth year because the female was killed in an early-season storm during the laying period in 1989. Before her death, this pair laid nine eggs, of which they hatched six and fledged five (the minimum

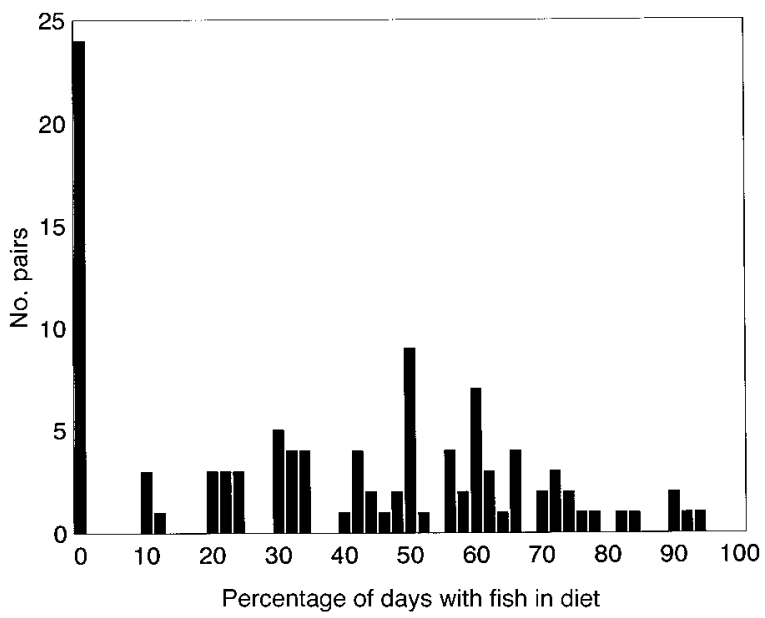

FIG. 6. Distribution of diets of individually recognizable Western Gulls. Units along the ordinate represent the percentage of days in which fish were taken by each pair in a typical year, such that 0 means no fish were taken and 100 means that only fish were taken. 


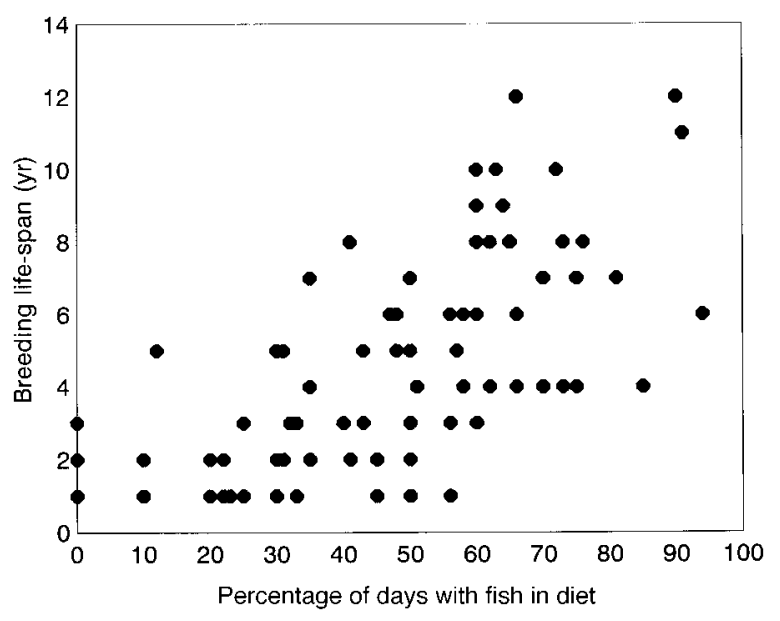

FIG. 7. The relationship between number of years as breeder (as in Fig. 1) and percentage of fish in diet of adult (parent) Western Gulls during all years of the study. The ordinate is the percentage of fish in the diet, as in Fig. $6\left(r^{2}\right.$ $=0.579, P<0.001)$.

number sufficient to replace themselves in the breeding population). All pairs with reproductive life-spans $>10$ yr showed diets that consisted of $\geq 60 \%$ fish (Fig. 7).

Similar patterns were observed with regard to laying and hatching of eggs. There was a significant correlation both between diet and total egg production $\left(r^{2}\right.$ $=0.62, P<0.001$; Fig. 8$)$, and between diet and total hatchling production $\left(r^{2}=0.64, P<0.001\right.$; Fig. 9). No pair that laid or hatched $>10$ eggs took a diet that did not consist of $\geq 30 \%$ fish. Conversely, all pairs that laid and hatched $>25$ eggs took diets consisting of a minimum of $60 \%$ fish, and two pairs producing $>30$ eggs and hatching $\sim 30$ chicks took diets consisting of $>90 \%$ fish.

As with other variables, diet is correlated with life-

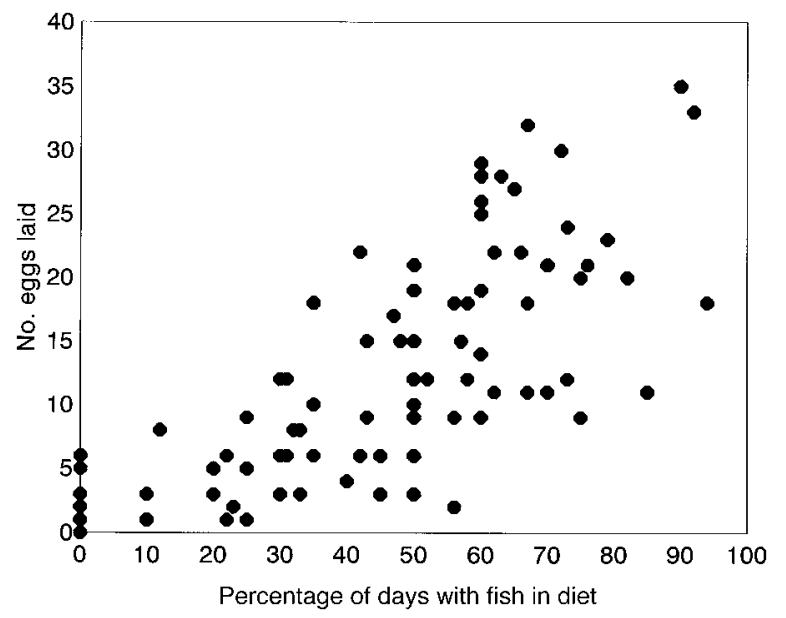

FIG. 8. The relationship between number of eggs laid (see Fig. 2) and percentage of fish in diet of adult Western Gulls during all years of the study. The ordinate is the percentage of fish in diet, as in Fig. $6\left(r^{2}=0.62, P<0.001\right)$.

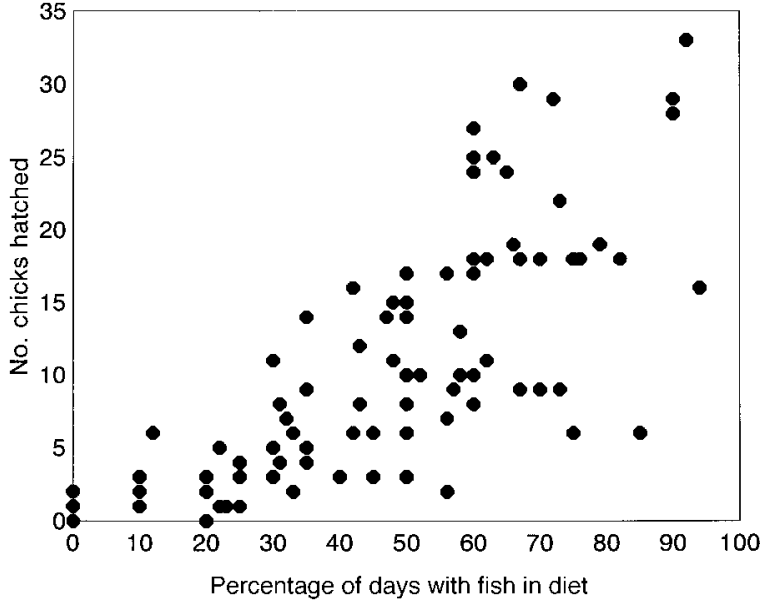

FIG. 9. The relationship between total hatchling production (Fig. 3) and percentage of fish in diet of adult Western Gulls during all years of the study, as in Fig. $6\left(r^{2}=0.64\right.$, $P<0.001)$.

time fledgling production $\left(r^{2}=0.61, P<0.001\right.$; Fig. 10). All pairs fledging more than five chicks over their breeding lifetime took a diet consisting of $\geq 35 \%$ fish. Only two pairs fledging $>10$ chicks took diets of $<50 \%$ fish, and no pair fledging more $>20$ chicks over their reproductive life-span took a diet of $<60 \%$ fish $(P<$ 0.001 using a $\chi^{2}$ test). Unlike laying and hatching, however, the four pairs taking $>90 \%$ fish did not fledge the most chicks, although three of these pairs did fledge $>25$ chicks.

During the course of our study, 757 chicks fledged from the subcolony. Over $60 \%$ of these chicks (463 fledglings) were produced by the 30 pairs (28\% of all pairs studied) that had diets consisting of $\geq 60 \%$ fish, which is significantly higher than expected $(P<0.0001$ using a $\chi^{2}$ test; $d f=1$ ).

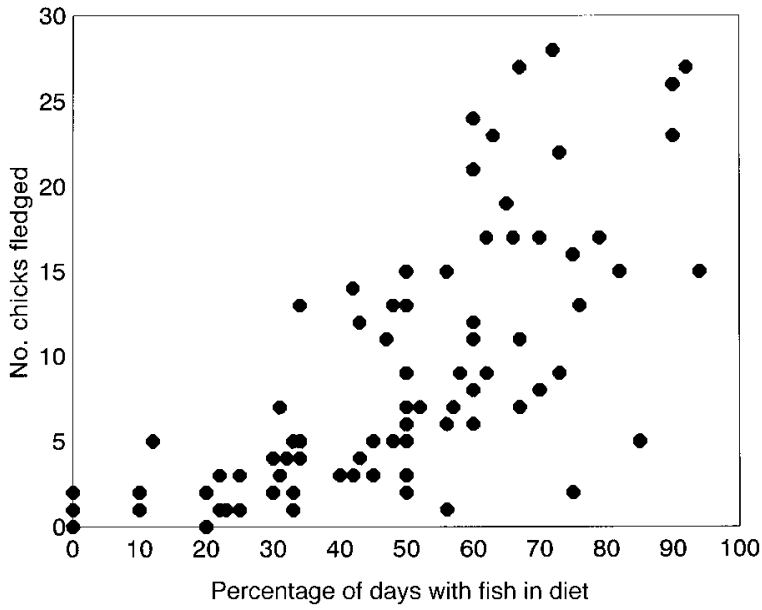

FIG. 10. The relationship between number of fledged offspring (see Fig. 4) and percentage of fish in the diet, as in Fig. $6\left(r^{2}=0.609, P<0.001\right)$. 


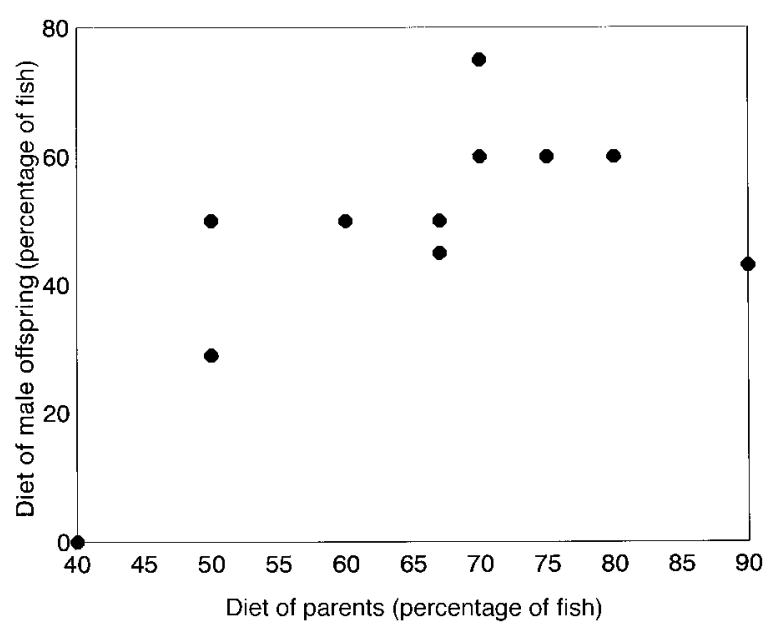

FIG. 11. Relationship between diet of male offspring and diet of parents, defined as percentage of days with fish in the diet, as in Fig. $6\left(r^{2}=0.404,0.01<P<0.05\right)$.

\section{Diet choice in new recruits}

The potential significance of individual variation in diet choice is even more striking when we examine the diets of banded offspring produced on our study colony that returned to breed within the colony. All 11 banded chicks in this category were male, and established breeding territories that were within $50 \mathrm{~m}$ of their natal territories. Only one of these young males was the offspring of a pair that had taken a diet averaging $<50 \%$ fish per season over their reproductive life-spans (the parents of this male averaged $40 \%$ fish). This male was the only breeding offspring that took no fish in his diet during his two breeding seasons, when he and his mate produced and hatched four eggs, but fledged only a single chick. The remaining 10 males were produced by pairs that took $50-90 \%$ fish in their diets. Diets of young males during their first year of breeding were correlated with the diets of their parents $\left(r^{2}=0.404\right.$, $0.01<P<0.05)$, as most took $50-75 \%$ fish in their diets (Fig. 11).

Of the six pairs that established themselves in the colony in 1988 and bred for the next seven years until the end of the study, five produced a male that was banded on the colony. One male that hatched on the colony bred first in his fourth spring in 1986, and continued to breed successfully for the remaining nine years of the study. Three other young males that hatched on the colony established themselves in 1990 and 1991, and bred successfully each year until the termination of the study.

Overall, nine of the 10 males whose parents took a high percentage of fish in their diets have been successful breeders. During the same period (1986-1992), in comparison, 71 other pairs (unbanded as chicks) established territories on the colony, but only six of these pairs (8\%) bred each year; and 41 of these pairs bred for only a single year. The difference between banded male offspring of parents with diets high in fish vs. pairs unbanded as chicks, establishing during the same period, is highly significant $(P<0.001$ using a $\chi^{2}$ test).

In addition to the 11 banded males, seven female gulls banded as chicks on our study colony were observed breeding in other areas on Alcatraz during our study. Female gulls are less philopatric than males, as was expected; in general, male birds show much stronger natal philopatry than do females (Greenwood 1980, Greenwood and Harvey 1982). In contrast to male recruits, banded female offspring during their first year of breeding showed no dietary relationship to their parents $\left(r^{2}=0.018, P=0.776\right.$; Fig. 12). All of these females were daughters of parents that took $44-73 \%$ fish in their diets, yet only one of these females was a member of a pair that took $>50 \%$ fish. It is noteworthy that the female with the highest percentage of fish in her diet was the only banded female that bred successfully for more than three years.

In gulls, males hatch disproportionately more often from the second-laid, or B, egg (Sayce and Hunt 1987, Meathrel et al. 1988; R. Pierotti, unpublished data); of the 11 banded male recruits, nine hatched from $\mathrm{B}$ eggs. The other two cases were a $\mathrm{C}$ chick that was the sole surviving chick in his brood of three, and an A chick from a nest where both the A and B chick from the same brood became successful breeders. This was the only instance we recorded in which more than a single bird raised by the same parents returned to breed within the colony.

In contrast to the male recruits, five of the seven female recruits were A chicks, one was a B chick, and one was a $\mathrm{C}$ chick from a brood in which all three chicks fledged. The one female that took $>50 \%$ fish in her diet was the only chick surviving to fledge from her parents' brood in the year she was hatched.

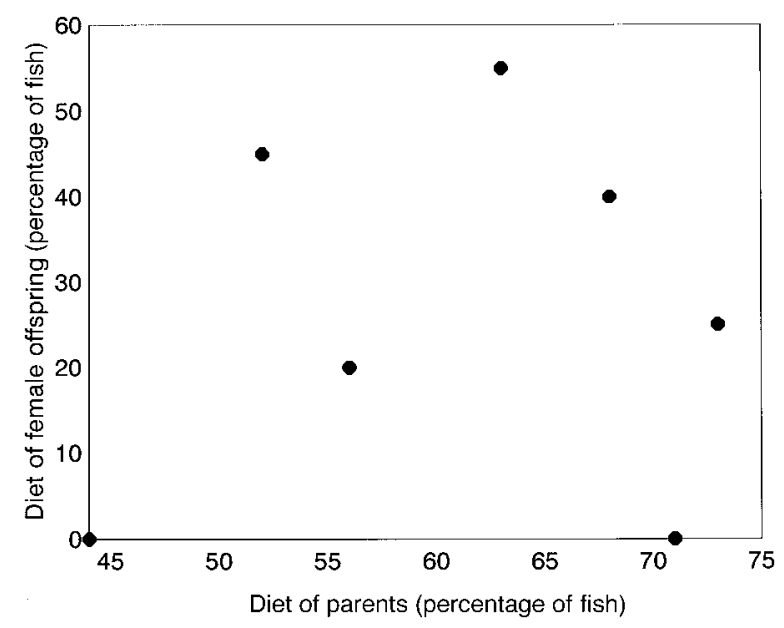

FIG. 12. Relationship between diet of female offspring and diet of parents, defined as percentage of days with fish in the $\operatorname{diet}\left(r^{2}=0.018, P=0.776[\mathrm{NS}]\right)$. Note that the ordinate begins at 0.45 for the parental diet. 


\section{Discussion}

The results of this study have implications for the study of the evolution of reproductive tactics, including the existence of trade-offs in variable or heterogeneous environments (Bell 1980, Roff 1992, Stearns 1992). Large differences in life-span and both short- and longterm breeding success are attributable to individual differences in choice of diet, which appear to result from differences in early experience, social role, and behavioral development. The major impact of diet appears to be increased adult breeding life-span, but effects on clutch size and viability of offspring, also attributable to diet, show up in both annual and long-term breeding performance.

Excellent, long-term studies of known-age banded Western Gulls by Point Reyes Bird Observatory (PRBO) on Southeast Farallon Island have revealed some important patterns in reproductive tactics. Results of the PRBO studies and our results complement each other and provide a more complete picture of gull reproduction. First, the PRBO studies suggest that, after controlling for effects of age, Western Gull breeding performance varies significantly among years: food availability explains $31 \%$ of the annual variation in clutch size and $72 \%$ of the annual variation in number of fledglings produced (Sydeman et al. 1991). It is important to note, however, that our study is based on actual gull diets, whereas PRBO researchers based their assessments of food availability on indirect measures; i.e., Western Gull annual reproductive success was positively related to the proportion of rockfish, assessed using National Marine Fisheries Service trawls, stomach contents of salmon, and the diets of Common Murre, Uria aalge, chicks (Ainley and Boekelheide 1990, Sydeman et al. 1991). What is important, however, is that, as in our study, PRBO found that fish availability was a crucial determinant of high reproductive performance in Western Gulls.

PRBO found pronounced age effects during years of poor fish availability, with significantly smaller C eggs and low fledging success for young (inexperienced) parents (Sydeman et al. 1991, Sydeman and Emslie 1992). It was also found that the age of the male member of the pair was more important than the age of the female in determining success for first-time breeders, whereas prior breeding success was more important than age for female success (Pyle et al. 1991). PRBO surmised that this situation resulted because "age-specific variation in reproductive success is due, in part, to increases in foraging efficiency with age (in males), which could influence body condition" (Sydeman and Emslie 1992).

The PRBO studies also report a major difference in breeding performance between first-time and experienced breeders (Pyle et al. 1991), and argue that experience gained during the initial breeding season is most important; experiential effects do not much im- prove reproductive performance after the first season (Sydeman et al. 1991). Our results suggest that this poorer performance in the first breeding season may actually be the result of pooling results from individuals taking low-quality (low-fish) and individuals taking high-quality (high-fish) diets. We found that young birds on high-fish diets did as well in their initial year of breeding as in subsequent years, whereas individuals taking high-refuse diets had very low success.

PRBO's most recent work argues that Western Gulls show trade-off-based "costs of reproduction" similar to those predicted from life history theory (Pyle et al. 1997). This study was based on 2102 breeding attempts by 898 individual birds, yielding an average of 2.3 breeding seasons per individual. In contrast, our birds averaged 4.0 breeding seasons. This difference probably results from the fact that PRBO restricted their data set to 3-9 yr-old birds with $0-4$ yr of breeding experience "because of inadequate samples of older, more experienced gulls" (Pyle et al. 1997). In relation to our results, the "cost of reproduction" described by PRBO may be an artifact resulting from pooling successful and unsuccessful birds during their first few breeding seasons, in combination with their truncated distribution. Our most successful birds were a minimum of 13-15 yr old with 10-12 yr of breeding experience. From our results, it appears that costs of reproduction are borne almost exclusively by individuals that show both poor reproductive performance and low survival. In contrast, our most successful pairs showed both high reproductive success and good survival.

The results generated by PRBO and by other studies of long-term breeding success in gulls (e.g., Thomas and Coulson 1988, in Clutton-Brock 1988) can lead to a circular argument, in which it is assumed that variation in reproductive performance reflects variation in individual quality and vice versa (Sydeman et al. 1991). For example, age-specific breeding performance may improve with previous breeding experience and foraging efficiency, or this could be a statistical artifact resulting from individual variation, if only the highquality animals survive to the oldest age classes (Sydeman et al. 1991). The way out of this conundrum is to provide a measure of quality that is not circular. Our results provide a noncircular, independent metric that is not based solely on measures of breeding performance. The percentage of fish in the diet of individual pairs (diets high in fish indicate high-quality birds) can be independently tested against lifetime reproductive output.

The large differences in fitness between individuals taking high-fish diets and those taking low-fish diets in our study create the potential for rapid action by natural selection (Arnold and Wade 1984, Grafen 1988). The opportunity for selection estimated for our population $(I=1.13)$ indicates a strong potential selective response; of the measurements of $I$ made in other field studies of monogamous vertebrates, only in 
studies of Galapagos finches did $I$ exceed 1.13 (Price 1984). It is also significant that our estimate is based on lifetime reproductive success, whereas estimates in Price (1984) and other studies have been based only on annual reproductive success (Arnold and Wade 1984, Endler 1986, Downhower et al. 1987). Thus, if a genetic trait existed that increased the tendency of gulls to take fish, it could spread rapidly.

Selection for fish specialization is constrained, however, by the ability of some birds to effectively locate and capture fish, which are the most risk prone (sensu Caraco 1981), unpredictable, and difficult to exploit of the wide variety of prey items taken by gulls. Fish specialization is further constrained by periodic crashes of fish populations resulting either from climatic events such as El Niño, or from human overfishing (Pierotti 1981, Ainley and Boekelheide 1991; M. S. Rodway and H. M. Regehr, unpublished manuscript). Thus, the combination of variation in both environmental conditions and individual experience will maintain two or more alternate foraging tactics that allow gulls to survive periods when they lack sufficient food resources to reproduce, or even to reproduce during periods when other, more specialized, seabirds (e.g., terns, alcids) fail to breed.

Most recruits to our colony do not take large amounts of fish in their diets. Therefore, the tendency to take fish is probably passed from parents to offspring by other than genetic means, possibly through learning. Our results raise the question of how a preference for fish could be passed from parents to sons, but apparently not to daughters.

In gulls, the dominant offspring within a brood is known to defend one or both of its parents against its siblings as a "feeding territory" away from the natal colony (Drury and Smith 1968). The dominant offspring is typically the oldest and largest male within a brood, or the sole surviving male (Briggs 1977; R. Pierotti, unpublished data). Nearly all of our male recruits were B chicks or the only surviving male offspring within a brood and, thus, were likely to be dominant chicks with access to their parents after fledging. Similarly, the only banded female recruit that took a diet of mostly fish was the sole survivor from her brood; because she had no male sibling to exclude her, she also could have accompanied her fish-taking parent(s) after fledging. Thus, the most likely mechanism by which a preference for fish could be passed primarily from parents to sons is through offspring learning to forage directly from their parents, i.e., through vertical transmission of an acquired trait (Feldman and Laland 1996).

This suggests that the large numbers of birds that feed largely or primarily on human refuse (scavengers) are probably excluded siblings (females and smaller males), which are prevented by their dominant sibling from accompanying their parent(s) during foraging, and which congregate around predictable sources of lower quality food, such as refuse dumps, picnic areas, or intertidal zones (e.g., Niebuhr 1983, Sibly and McLeery 1983, Irons et al. 1986). This would also explain why most birds do not take fish, because successful breeding pairs often produce two subordinate chicks for each dominant chick.

Around predictable food sources such as refuse, young gulls learn to forage from other birds, i.e., through horizontal transmission of an acquired trait (Feldman and Laland 1996). These predictable foraging areas contain abundant supplies of food that are adequate to allow fledged offspring to survive. However, the food available in these areas may be nutritionally inadequate for chick or mate feeding, or for formation of large, well-supplied eggs (Pierotti and Bellrose 1986, Pierotti and Annett 1987, 1990, 1991). As a consequence, individuals employing the scavenging mode of foraging are fully able to survive, but are much less successful at reproduction. Their smaller clutch sizes, reduced hatching success, and shortened reproductive life-spans may result from their initial attempts to reproduce while under nutritional stress.

\section{ACKNOWLEDGMENTS}

We thank the National Park Service for permission to work on Alcatraz. We thank K. Armitage, J. Ellis, T. Good, R. Holt, and T. Peterson for comments on early drafts, and B. Maurer and two anonymous reviewers for comments on a later draft.

\section{Literature Cited}

Ainley, D. G., and R. Boekelheide. 1990. Seabirds of the Farallon Islands. University of California Press, Berkeley, California, USA.

Annett, C. A., and R. Pierotti. 1989. Chick hatching as a trigger for dietary switches in Western Gulls. Colonial Waterbirds 12:4-11.

Arnold, S. J., and M. J. Wade. 1984. On the measurement of natural and sexual selection: applications. Evolution 38: 720-734.

Bell, G. 1980. Costs of reproduction and their consequences. American Naturalist 116:45-76.

Boyce, M. S., and C. M. Perrins. 1988. Optimizing Great Tit clutch size in a fluctuating environment. Ecology 68 : 142-153.

Briggs, K. T. 1977. Social dominance in young Western Gulls: its importance in survival and dispersal. Dissertation. University of California, Santa Cruz, California, USA.

Caraco, T. 1981. Risk sensitivity and foraging groups. Ecology 62:527-531.

Clutton-Brock, T. H. 1988. Reproductive success. University of Chicago Press, Chicago, Illinois, USA.

Clutton-Brock, T. H., G. R. Iason, S. D. Albon, and F. E. Guinness. 1982. Effects of lactation on feeding behaviour and habitat use in wild red deer hinds. Journal of Zoology, London 198:227-236.

Downhower, J., L. Blumer, and L. Brown. 1987. Opportunity for selection: an appropriate measure for evaluating variation in potential for selection. Evolution 41:1395-1400.

Drury, W. H., and W. J. Smith. 1968. Defense of feeding areas by adult Herring Gulls and intrusion by young. Evolution 22:193-201.

Endler, J. 1986. Natural selection in the wild. Princeton University Press, Princeton, New Jersey, USA.

Ens, B. J., F. J. Wessing, and R. H. Drent. 1995. The despotic distribution and deferred maturity: two sides of the same coin. American Naturalist 146:625-650. 
Feldman, M. W., and K. N. Laland. 1996. Gene-culture coevolutionary theory. Trends in Ecology and Evolution 11: 453-457.

Fretwell, S. D., and H. L. Lucas, Jr. 1970. On territorial behavior and other factors influencing habitat distribution in birds. I. Theoretical development. Acta Biotheoretica 19: $16-36$.

Grafen, A. 1988. The uses of data on lifetime reproductive success. Pages 454-471 in T. H. Clutton-Brock, editor. Reproductive success. University of Chicago Press, Chicago, Illinois, USA.

Grant, B. R., and P. R. Grant. 1989. Evolutionary dynamics of a natural population. University of Chicago Press, Chicago, Illinois, USA.

Grant, B. R., and P. R. Grant. 1996. High survival of Darwin's finch hybrids: effects of beak morphology and diets. Ecology 77:500-509.

Grant, P. R., and B. R. Grant. 1994. Phenotypic and genotypic effects of hybridization in Darwin's finches. Evolution 48:297-316.

Greenwood, P. J. 1980. Mating systems, philopatry, and dispersal in birds and mammals. Animal Behaviour 28:11401162.

Greenwood, P. J. and P. H. Harvey. 1982. The natal and breeding dispersal of birds. Annual Review of Ecology and Systematics 13:1-21.

Irons, D. B., R. G. Anthony, and J. A. Estes. 1986. Foraging strategies of Glaucous-winged Gulls in a rocky intertidal community. Ecology 67:1460-1474.

Kadlec, J., and W. H. Drury. 1968. Structure of the New England Herring Gull population. Ecology 49:222-233.

Meathrel, C. E., J. P. Ryder, and B. M. Termatt. 1988. Size and composition of Herring Gull eggs: relationship to position in laying sequence. Colonial Waterbirds 11:115-124.

Newton, I. 1989. Lifetime reproduction in birds. Academic, New York, New York, USA

Niebuhr, V. 1983. Feeding strategies and incubation behaviour of wild Herring Gulls. Animal Behaviour 31:708-717.

Partridge, L. 1989. Lifetime reproductive success and life history evolution. Pages 421-440 in I. Newton, editor. Lifetime reproduction in birds. Academic, New York, New York, USA.

Paynter, R. 1966. A new attempt to construct life tables for Kent Island Herring Gulls. Bulletin of the Museum of Comparative Zoology, Harvard University 133(11):489-528.

Pierotti, R. 1981. Male and female parental roles in the Western Gull under different environmental conditions. Auk 98: 532-549.

. 1982. Habitat selection and its effect on reproductive output in the Herring Gull in Newfoundland. Ecology 63 : $854-868$.
1987. Behavioral consequences of habitat selection in the Herring Gull. Studies in Avian Biology 10:119-128.

Pierotti, R., and C. A. Annett. 1987. Reproductive consequences of specialization and switching in an ecological generalist. Pages 417-442 in A. C. Kamil, J. R. Krebs, and H. R. Pulliam, editors. Foraging behavior. Plenum Press, New York, New York, USA.

Pierotti, R., and C. A. Annett. 1990. Diet and reproductive performance in seabirds. BioScience 40:568-574.

Pierotti, R., and C. A. Annett. 1991. Diet choice in the Herring Gull: effects of constraints imposed by reproduction and ecology. Ecology 72:319-328.

Pierotti, R., and C. A. Annett. 1995. Western Gull. Birds of North America. Philadelphia Academy of Sciences, Philadelphia, Pennsylvania, USA.

Pierotti, R., and C. A. Bellrose. 1986. Proximate causation and the third chick disadvantage in gulls. Auk 103:401407.

Price, T. 1984. The evolution of sexual size dimorphism in Darwin's finches. American Naturalist 123:500-518.

Pyle, P., L. B. Spear, W. J. Sydeman, and D. G. Ainley. 1991. The effects of experience and age on the breeding performance of Western Gulls. Auk 108:25-33.

Pyle, P., N. Nur, W. J. Sydeman, and S. D. Emslie. 1997. Cost of reproduction and the evolution of deferred breeding in the Western Gull. Behavioral Ecology 8:140-147.

Roff, D. 1992. Evolution of life histories. Chapman and Hall, New York, New York, USA.

Sayce, J. R., and G. L. Hunt. 1987. Sex ratios of prefledging Western Gulls. Auk 104:33-37.

Sibly, R. M., and R. H. McLeery. 1983. Increase in the weight of herring gulls while feeding. Journal of Animal Ecology 52:35-50.

Spear, L. B., H. R. Carter, T. M. Penniman, J. P. Penniman, and D. G. Ainley. 1987. Survivorship and mortality factors in a population of Western Gulls. Pages 44-56 in J. L. Hand, W. E. Southern, and K. Vermeer, editors. Studies in avian biology. Volume 10. Allen Press, Lawrence, Kansas, USA.

Spear, L. B, and N. Nur. 1994. Brood size, hatching order, and hatching date: effects of four life-history stages from hatching to recruitment in western gulls. Journal of Animal Ecology 63:283-298.

Stearns, S. 1992. Evolution of life histories. Oxford University Press, Oxford, UK.

Sydeman, W. J., and S. D. Emslie. 1992. Effects of parental age on hatching asynchrony, egg size, and third-chick disadvantage in Western Gulls. Auk 109:242-248.

Sydeman, W. J., J. F. Penniman, T. M. Penniman, P. Pyle, and D. G. Ainley. 1991. Breeding performance in the western gull: effects of parental age, timing of breeding, and year in relation to food availability. Journal of Animal Ecology 60:135-149. 